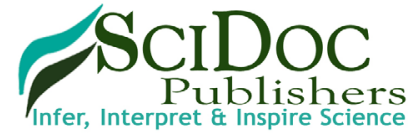

\section{A Comparitive Study Of Bupivacaine 0.5\% And Ropivacaine 0.5\% For Ultrasound Guided Supraclavicular Brachialplexus Block}

Research Article

H S Prajwal Patel*, Sarvesh B, B T Shivaramu

Associate Professor, Department of Anaesthesia, Adichunchanagiri Institute of Medical Sciences, Mandya, Karnataka, India.

\title{
Abstract
}

Background: Supraclavicular Brachial plexus block provides safe, effective, low cost anaesthesia with excellent post operativeanalgesia.With the advent of ultrasound guidance establishing the blockade has been easier with reduced drug dosage and less complications.

Objective: To compare the effect of bupivacaine $0.5 \%$ \&ropivacaine $0.5 \%$ used for ultrasound guided supraclavicular brachial plexus block with respect to onset and duration of sensory blockade, onset and duration of motor blockade, duration of analgesia.

Methods: 60 patients of ASA class 1 and 2 for upper limb surgical procedures were randomly allocated into two groups of 30 each, Group B - i.e Bupivacaine group receives $20 \mathrm{ml}$ Bupivacaine $0.5 \%$ ( $5 \mathrm{mg} / \mathrm{ml}$ ), Group R - i.e Ropivacaine group receives $20 \mathrm{ml}$ Ropivacaine $0.5 \%$ ( $5 \mathrm{mg} / \mathrm{ml}$ ).With ultrasound guidance supraclavicular brachialplexus block was administered. Testing for onset of sensory blockade was done using pin prick method,motor block was assessed using modified bromage scale, post operatively patients would be assessed for the duration of sensory and motor blockade.

Results: The present study shows that the onset of sensory,motor blocks was significantly earlier in bupivacaine $0.5 \%$ group (Group B) in comparision with ropivacaine $0.5 \%$ group (Group R ).The duration of motor, sensory block and duration of analgesia was longer in Bupivacaine $0.5 \%$ group compared with Ropivacaine $0.5 \%$ group.

Conclusion: Bupivacaine $0.5 \%$ has early onset of sensory blockade ,early onset of motor blockade,prolonged duration of sensory blockade, motor blockade, prolonged duration of analgesia when compared to ropivacaine $0.5 \%$ at equal volumes when used for supraclavicular brachial plexus block under ultrasound guidance without any adverse effects.

Keywords: Bupivacaine; Ropivacaine; Ultrasound; Supraclavicular Brachialplexus Block.

\section{Introduction}

Peripheral nerve blocks have become important in clinical practice because of their role in post operative pain relief, shortening of patient recovery time $\&$ avoiding risks and adverse effects of general anaesthesia [1]. Brachial plexus block at the supraclavicular level provides anaesthesia for the upper limb surgeries by blocking the middle \& lower plexus (Median, Radial and Ulnar N).

The use of ultrasound has gained popularity in the field of regional anaesthesia, as it has many advantages over the conventional technique of nerve stimulation. It provides a direct visualization of the anatomic structures and helps in minimizing vascular punctures by allowing a dynamic vision of the needle advance- ment and local anaesthetic spread.

Ultrasound guided supraclavicular brachial plexus block has become popular currently, owing to detection of anatomical variation of brachial plexus, accuracy of needle placements and avoidance of needle related complications such as injury to blood vessels, pneumothorax $\&$ local anesthetictoxicity [2].

Bupivacaine is a long acting local anaesthetic. Due to its long duration of action and combined with its high quality sensory blockade compared to motor blockade it has been the most commonly used local anaesthetic for peripheral nerve blocks.

Ropivacaine is a newer, long acting local anaesthetic whose neuronal blocking potential used in peripheral nerve blockade seems

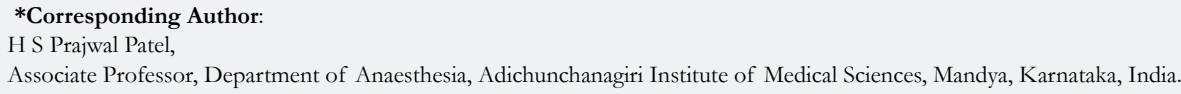

Copyright: H S Prajwal Patel ${ }^{\circ}$ 2021. This is an open-access article distributed under the terms of the Creative Commons Attribution License, which permits unrestricted use, distribution and reproduction in any medium, provided the original author and source are credited. 
to be equal or superior to bupivacaine. Studies shows that it has significantly greater safety margin over bupivacaine because of lower CNS and cardiac toxicity and hence can be used in higher concentrations. One of the drawbacks of ropivacaine mentioned is its less intense motor blockade compared to bupivacaine [3].

Hence here is an attempt was made through the study to compare bupivacaine $0.5 \%$ with ropivacaine $0.5 \%$ in supraclavicular brachial plexus block under ultrasound guidance.

\section{Materials And Methods}

A prospective randomized study is planned.60 patients of ASA I and II physical status aged 18-55yrs will be scheduled to undergo elective upper limb surgical procedures. They will be randomly allocated into two groups by computer generated randomization into

Group B - i.e Bupivacaine group receives $20 \mathrm{ml}$ Bupivacaine $0.5 \%(5 \mathrm{mg} / \mathrm{ml})$

Group R - i.e Ropivacaine group receives $20 \mathrm{ml}$ Ropivacaine $0.5 \%(5 \mathrm{mg} / \mathrm{ml})$

\section{Inclusion criteria:}

a) Age group between 18-45 yrs

b) ASA I and II

c) Patients with body weight of $50-80 \mathrm{kgs}$

d) Who gives informed written consent

\section{Exclusion criteria:}

a) Patients not willing to give informed consent

b) Unco-operative patients

c) Local pathology at the site of injection

d) History of bleeding disorders, convulsions, severe neurological deficit and allergy

e) History of major organ system illness (cardiac, respiratory, hepatic and renal failure)

\section{Methodology}

After obtaining approval and clearance from the institutional ethical committee, the patients fulfilling the inclusion criteria will be enrolled for the study after obtaining informed consent.

Patients admitted for upper limb surgical procedures will be taken up for the study.

All the patients will undergo pre anaesthetic evaluation and routine necessary investigations will be carried out. Patients coming under ASA I and II category would be explained about the procedure in detail.

A total of 60 no of patients will be randomly allocated into two groups of 30 each

Group B - i.e Bupivacaine group receives $20 \mathrm{ml}$ Bupivacaine $0.5 \%(5 \mathrm{mg} / \mathrm{ml})$
Group $\mathrm{R}$ - i.eRopivacaine group receives $20 \mathrm{ml}$ Ropivacaine $0.5 \%$ $(5 \mathrm{mg} / \mathrm{ml})$

All the patients will be prescribed $0.5 \mathrm{mg}$ of alprazolam and $150 \mathrm{mg}$ of ranitidine orally to be taken on the night before surgery. Patients will also be advised to be nil orally from $10 \mathrm{pm}$ onward on the night before surgery.

Ensuring overnight NPO status, on arrival in the OT, patient will be placed in supine position on OT table and monitors will be connected HR, NIBP, ECG and SPO2 will be recorded as per standard ASA guidelines. Premedication which includes injection midazolam $0.04 \mathrm{mg} / \mathrm{kg}$ iv would be administered after obtaining an IV access with $18 \mathrm{G}$ catheter. Under strict aseptic precautions supraclavicular brachial plexus block performed by ultrasound guided approach in plane technique.After real time visualization of brachial plexus by ultrasound, needle was placed near the plexus, following negative aspiration of blood, drug solution was injected around the brachial plexus.

Testing for onset of sensory blockade will be done using pin prick method, the assessment will be made every 1 minute thereafter till patients feels no pain to pinprick. Motor block will be assessed using modified Bromage scale. After the surgical procedure patients would be assessed for the duration of sensory and motor blockade and the time noted. Assessment of sensory blockade will be on VAS scale. Cessation of analgesia is taken at the time when the patient asks for rescue analgesia. Any untoward effects during the procedure will be noted down.

\section{Scoring Systems}

\section{Sensory block}

The sensory block will be assessed by pin prick with 25 gauge needle.

\section{Sensory Block}

\section{Sharp pain}

1. Touch sensation only

2. Not even touch sensation

\section{Pain rating scale}

\section{Visual analouge scale}

A simple assessment tool consisting of a $10 \mathrm{~cm}$ line with 0 on one end, representing no pain, and 10 on the other, representing the worst pain over ever experienced, with a patient marks to indicate the severity of his or her pain.

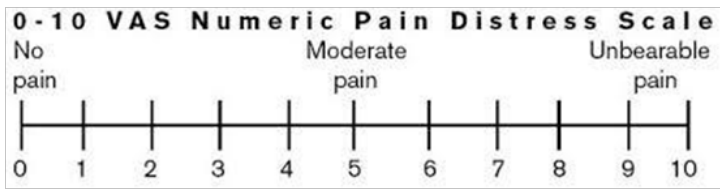

\section{Motor block}

\section{Modified Bromage scale}


0 - Able to raise the extended arm to $90^{\circ}$ for a full 2 secs.

1 - Able to flex the elbow and move the fingers but unable to raise the extended arm.

2 - Unable to flex the elbow but able to move the fingers.

3 - Unable to move the arm, elbow or fingers.

Onset of motor blockade will be considered when there will be Grade 1 motor blockade. Peak motor block will be considered when there will be Grade 3 motor blockade.

\section{Statistical Analysis}

Statistical analysis of data will be done using student $t$ test ( $\mathrm{z}$ test) for parametric data. Non parametric data will be analyzed by Chisqure test. Statistical significance was considered if $\mathrm{P}$ value $<0.05$.

\section{Results And Observation}

No statistical significance was found in demographic profile of age, sex and weight, thereby making the two groups similar and comparable.

In Group B , the mean onset time of sensory blockade and motor blockade was $17.70 \pm 2.35 \mathrm{~min}$ and $25.43 \pm 2.22 \mathrm{~min}$ Respectively when compared to Group $\mathrm{R}$ havingonset time of sensory blockade and Motor blockade of $22.13 \pm 3.05 \mathrm{~min}$ and $27.90 \pm 1.88$ min Respectively. Onset time of Sensory and Motor blockade was earlier in Group B when compared with Group $\mathrm{R}$. The p value was $<0.001$ which is statistically highly significant.

In Group B , the Mean Duration of Sensory blockade and Motor blockade was $342.00 \pm 47.66 \mathrm{~min}$ and $369.00 \pm 41.05 \mathrm{~min}$ Respectively when compared to Group R having Mean Duration of sensory blockade and Motor blockade of $302.00 \pm 42.38 \mathrm{~min}$ and $336.00 \pm 37.29$ min Respectively .

Duration of Sensory and Motor blockade was prolonged in
Group B when compared with Group R. The p value was 0.001 and 0.001 respectively which is statistically highly significant.

In Group B , the mean duration of analgesia was $372.00 \pm 42.86$ min when compared to Group $\mathrm{R}$ having mean duration of analgesia of $341.00 \pm 36.52 \mathrm{~min}$. Duration of analgesia was prolonged in Group B when compared with Group R . The p value was 0.004 which is statistically highly significant.

\section{Haemodynamic Parameters}

Intra operative and post block haemodynamic parameters like heart rate, systolic blood pressure, diastolic blood pressure, mean arterial pressure, peripheral oxygen saturation in percentage (SpO2) were normal in both the groups requiring no intervention and the differences between the two groups were statistically insignificant.

\section{Discussion}

This section is devoted for the discussion of the results of the present clinical study entitled "a comparitive study of bupivacaine $0.5 \%$ andropivacaine $0.5 \%$ for ultrasound guided supraclavicular brachialplexus block"conducted to compare the effects of bupivacaine $0.5 \% 20 \mathrm{ml}$ andropivacaine $0.5 \% 20 \mathrm{ml}$ on the block characteristics, based on its objectives. After obtaining ethical committee clearance and written informed consent, 60 ASA status I and II patients, undergoing elective upper limb surgeries under ultrasound guided supraclavicular brachial plexus block, were randomly divided into two groups Group B and Group R (30 each) to receive bupivacaine $0.5 \% 20 \mathrm{ml}$ and ropivacaine $0.5 \% 20 \mathrm{ml}$ respectively.All patients were administered ultrasound guided supraclavicular brachial plexus block under aseptic precautions using the study drugs and the various parameters were studied.

In the present study ultrasound guided technique was chosen for administering supraclavicular brachial plexus block as it offers

Table 1. Comparison Of Group B And Group R On The Basisof Onset Time Of Sensory And Motor Blockade.

\begin{tabular}{|c|c|c|c|}
\hline Study variables & Group B & Group R & P value \\
\hline SENSORY ONSET TIME & $17.70 \pm 2.35$ & $22.13 \pm 3.05$ & $<0.001$ \\
\hline MOTOR ONSET TIME & $25.43 \pm 2.22$ & $27.90 \pm 1.88$ & $<0.001$ \\
\hline
\end{tabular}

Table 2. Comparison Of Group B And Group R On The Basis Of Duration Of Sensory And Motor Blockade.

\begin{tabular}{|c|c|c|c|}
\hline Study variables & Group B & Group R & P value \\
\hline $\begin{array}{c}\text { DURATION OF } \\
\text { SENSORY } \\
\text { BLOCKADE }\end{array}$ & $342.00 \pm 47.66$ & $302.00 \pm 42.38$ & 0.001 \\
\hline $\begin{array}{c}\text { DURATION OF } \\
\text { MOTOR } \\
\text { BLOCKADE }\end{array}$ & $369.00 \pm 41.05$ & $336.00 \pm 37.29$ & 0.001 \\
\hline
\end{tabular}

Table 3. Comparison Of Group B And Group R On The Basis Of Duration Of Analgesia.

\begin{tabular}{|c|c|c|c|}
\hline Study variables & Group B & Group R & P value \\
\hline $\begin{array}{c}\text { DURATION OF } \\
\text { ANALGESIA }\end{array}$ & $372.00 \pm 42.86$ & $341.00 \pm 36.52$ & 0.004 \\
\hline
\end{tabular}


Graph 1. Onset Time Of Sensory And Motor Blockade.

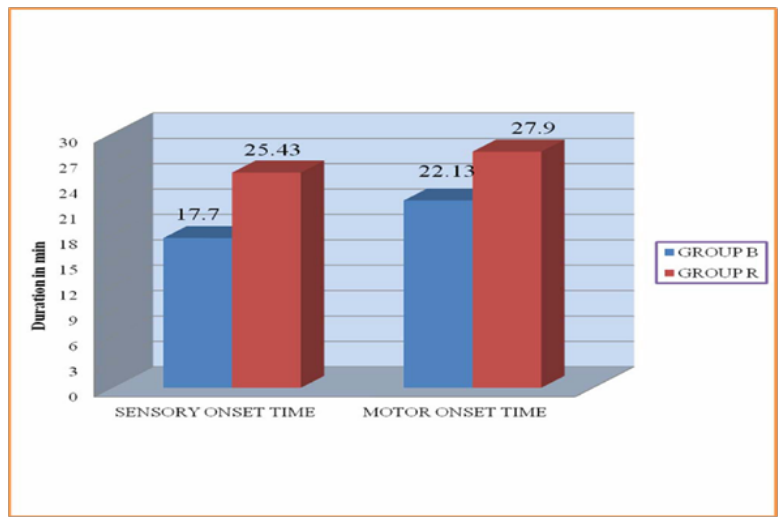

Graph 2. Duration Of Sensory And Motorblockade.

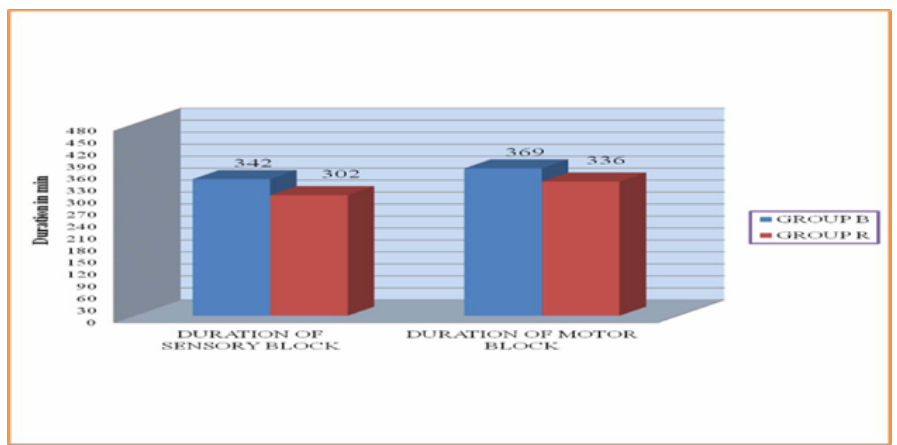

Graph 3. Comparision Of Duration Of Analgesia.

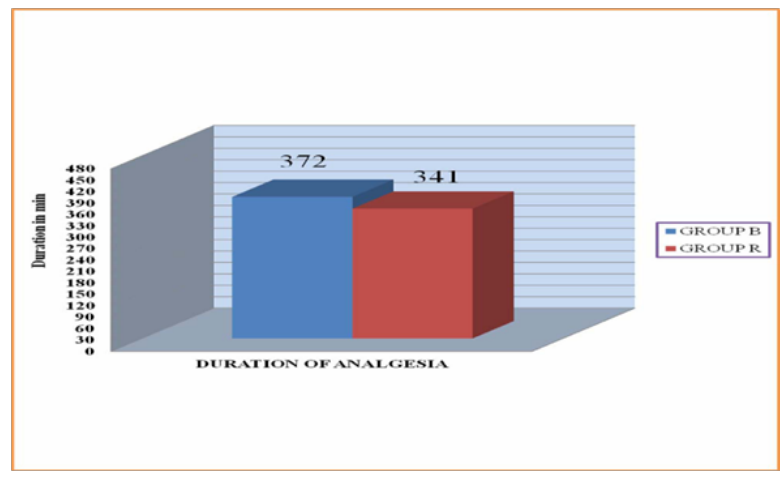

many advantages over the conventional technique of nerve stimulation and paraesthesia like, providing a direct visualization of the anatomical structures, dynamic vision of the needle advancement and local anaesthetic spread around the nerve roots. It has also been shown to reduce the number of needle passes or redirections needed to perform the block, provide enhanced sensory and motor blocks, allow shorter procedure times with fewer vascular punctures, it may also reduce the incidence of major block complications, as compared to the nerve stimulation technique.

The most commonly used local anaesthetics for peripheral nerve blocks are Lignocaine and Bupivacaine. The local anaestheticRopivacaine was chosen for the current study as it is a newer, long acting amide local anaesthetic with similar clinical properties, efficacy and duration of post-operative pain relief as that of the conventionally used bupivacaine, with the added advantage of being less lipophilic then bupivacaine, which accounts for its decreased central nervous system toxicity and cardiotoxicity, as proven by many authors like Usha badole et al., Ajai Vikram Singh et al., Veena Chatrath et al $[4,5]$.
A volume of $20 \mathrm{ml}$ of $0.5 \%$ of ropivacaine was used by Ushaet al. where they have used ultrasound for giving the block. So from above studies it was concluded that the volume of $0.5 \%$ ropivacaine and $0.5 \%$ bupivacaine required for ultrasound guided supraclavicular brachial plexus block was $20 \mathrm{ml}$. So the local anaesthetic volume of $20 \mathrm{ml}$ of $0.5 \%$ ropivacaine and $0.5 \%$ bupivacaine was chosen in the present study.

\section{Sensory Block}

\section{Time of onset of sensory}

In our study, we observed that onset time of sensory block was earlier in Bupivacaine group (Group B) having a mean value of $17.70 \pm 2.35$ minutes in comparision with Ropivacaine group (Group R) having a mean value of $22.13 \pm 3.05$ minutes. The difference between the two groups in terms of sensory block onset was statistically significant. $\mathrm{p}$ value $<0.001$.

These results were comparable with those obtained in the studies conducted by K Shaw, D Tripathi et al, Singelyn FJ et al $[6,7]$. 


\section{Motor Block}

\section{Time of onset of motor block}

In our study, we observed that onset time of Motor block was earlier in Bupivacaine group (Group B) having a mean value of 25.43 \pm 2.22 minutes in comparision with Ropivacaine group (Group R) having a mean value of $27.90 \pm 1.88$ minutes. The difference between the two groups in terms of sensory block onset was statistically significant. $\mathrm{p}$ value $<0.001$.

These results were comparable with those obtained in the studies conducted by K Shaw, D Tripathi et al, Singelyn FJ et al $[6,7]$.

\section{Duration of Motor block}

The Duration of Motor block was 369.00土41.05 minutes with Bupivacaine group and $336.00 \pm 37.29$ minutes with Ropivacainegroup. The duration of Motor block was longer in Bupivaine group compared with Ropivacaine group. The difference between the two groups was statistically significant. $\mathrm{p}$ value $<0.001$.

These results were comparable with those obtained in the studies conducted by Mcglade D.P, Kalpokas M.V, Mooney P.H et al [8, 9].

\section{Duration of Analgesia}

In our study duration of analgesia lasted for $372.00 \pm 42.86$ minutes with Bupivacaine group (Group B) and $341.00 \pm 36.52$ minutes with Ropivacaine group (Group R) with the difference between the two groups was statistically significant $P$ value $<0.001$. These results were comparable with those obtained in the studies conducted by Mcglade D.P, Kalpokas M.V, Mooney P.H et al, Hickey. R, Rowley. C.L, Ramamurthy. S et al [8, 9].

Hemodynamic parameters: Post block hemodynamic parameters like pulse rate, systolic, diastolic and mean arterial pressures were within normal limits in both the groups requiring no intervention.

Adverse effects: None of the patients had any complications and the incidence of intraoperative bradycardia, hypotension, pneumothorax, intravascular injection, post block nausea, vomiting, convulsions, neuralgia were nil in either group.

\section{Conclusion}

From the present study it can be concluded that Bupivacaine
$0.5 \%$ has early onset of sensory blockade, early onset of motor blockade, prolonged duration of motor blockade, prolonged duration of analgesia when compared to Ropivacaine $0.5 \%$ at equal volumes. Both the drugs maintain stable hemodynamic profile perioperatively and are devoid of any side effects at the concentration and volumes used for the study.

\section{References}

[1]. Partridge BL, Katz J, Benirschke K. Functional anatomy of the brachial plexus sheath: implications for anesthesia. Anesthesiology. 1987 Jun;66(6):7437. PubmedPMID: 3592273.

[2]. Kessler J, Gray AT. Ultrasound guidance for regional anaesthesia. In:Miller RD, Cohen NH, Eriksson LI, Fleisher LA, Wiener-Kronish JP, Young WL, editors. Miller's anaesthesia. 8th Ed. Philadelphia: Elsevier Saunders. 2015:1752-66.

[3]. Hickey R, Hoffman J, Ramamurthy S. A comparison of ropivacaine $0.5 \%$ and bupivacaine $0.5 \%$ for brachial plexus block. The Journal of the American Society of Anesthesiologists. 1991 Apr 1;74(4):639-42.

[4]. Ushabadole, Akshaysalunke. a comparative study of bupivacaine $0.5 \%$ and ropivacaine $0.5 \%$ in ultrasound guided axillary block. Global journal for research analysis. 2017:6(10):42-4.

[5]. Chatrath V, Sharan R, Kheterpal R, Kaur G, Ahuja J, Attri JP. Comparative evaluation of $0.75 \%$ ropivacaine with clonidine and $0.5 \%$ bupivacaine with clonidine in infraclavicular brachial plexus block. Anesth Essays Res. 2015 May-Aug;9(2):189-94. PubmedPMID: 26417126.

[6]. Tripathi D, Shah K, Shah C, Shah S, Das E. Supraclavicalar brachial plexus block for upper limb orthopedic surgery: A randomized, double blinded comparison between ropivacaine and bupivacaine. The Internet Journal of Anesthesiology. 2012 Nov;30(4).

[7]. Singelyn FJ. Clinical application of ropivacaine for the upper extremity. Curr Top Med Chem. 2001 Aug;1(3):219-25. PubmedPMID: 11895140.

[8]. McGlade DP, Kalpokas MV, Mooney PH, Chamley D. A comparison of $0.5 \%$ ropivacaine and $0.5 \%$ bupivacaine for axillary brachial plexus anaesthesia. Anaesthesia and intensive care. 1998 Oct 1;26(5):515.

[9]. Hickey R, Rowley CL, Candido KD, Hoffman J, Ramamurthy S, Winnie AP. A comparative study of $0.25 \%$ ropivacaine and $0.25 \%$ bupivacaine for brachial plexus block. Anesthesia and analgesia. 1992 Oct 1;75(4):602-6.

[10]. Vaghadiah, chan $v$, Ganapathy $S$ et alA Multicentric trial of Ropivacaine $7.5 \mathrm{mg} / \mathrm{ml}$ vs bupivacaine $5 \mathrm{mg} / \mathrm{ml}$ for supraclavicular brachial plexusAnesthesia . Canadian Journal of Anesthesia ,1999;46-10: pp 946-951.

[11]. Syed Ali Aasim, A.Srikanth Reddy, Anil Kumer, KarthikSatya S. Prospective study of the efficacy of clonidine added to ropivacaine as compared with ropivacaine alone in supraclavicular brachial plexus block. Ann.Int.Med. Den.Res. 2017;3(4):1-4.

[12]. Gupta K, Tiwari V, Gupta PK, Pandey MN, Singhal AB, Shubham G. Clonidine as an adjuvant for ultrasound guided supraclavicular brachial plexus block for upper extremity surgeries under tourniquet: A clinical study. J AnaesthesiolClinPharmacol. 2014 Oct;30(4):533-7. PubmedPMID: 25425780.

[13]. Lew E, Vloka JD, Hadžić A. Ropivacaine for peripheral nerve blocks: Are there advantages?. Techniques in Regional Anesthesia and Pain Management. 2001 Apr 1;5(2):56-9. 